\title{
Neurocognitive Disorders in Patients with HIV Infection with Virologic Suppression for More than 10 Years
}

\author{
André Filipe dos Santos-Silva1,2, Joana Margarida Almeida Alves, ${ }^{1,2}$, Isabel Ramos ${ }^{3}$, \\ Maria del Cármen Piñeiro-Calvo ${ }^{1}$, Cláudia Sousa ${ }^{4}$, Maria do Rosário Serrão", \\ António Carlos Eugénio Megre Sarmento ${ }^{1,2}$ \\ ${ }^{1}$ Infectious Diseases Department, São João Hospital Centre, Oporto, Portugal \\ ${ }^{2}$ Faculty of Medicine of the University of Oporto, Oporto, Portugal \\ ${ }^{3}$ Psychiatry and Mental Health Department, São João Hospital Centre, Oporto, Portugal \\ ${ }^{4}$ Neurology Department, São João Hospital Centre, Oporto, Portugal \\ Email: afss.md@gmail.com
}

How to cite this paper: Santos-Silva, A.F., Alves, J.M.A., Ramos, I., Piñeiro-Calvo, M.C., Sousa, C., Serrão, M.R. and Sarmento, A.C.E.M. (2017) Neurocognitive Disorders in Patients with HIV Infection with Virologic Suppression for More than 10 Years. World Journal of AIDS, 7, 59-66. https://doi.org/10.4236/wja.2017.71006

Received: February 25, 2017

Accepted: March 28, 2017

Published: March 31, 2017

Copyright $\odot 2017$ by authors and Scientific Research Publishing Inc. This work is licensed under the Creative Commons Attribution International License (CC BY 4.0).

http://creativecommons.org/licenses/by/4.0/

(c) $\underset{\mathrm{EY}}{ }$ Open Access

\begin{abstract}
Background: HIV-associated neurocognitive disorder (HAND) may appear in patients with viral and immunological response to treatment and remain unnoticed during the initial stage of the infection. The goal of this study is to evaluate the development and/or progression of HAND in patients with undetectable viral load for more than ten years. Methods: We included adult HIV-infected patients who were under antiretroviral treatment and had undetectable plasma viral load for more than ten years (blips were included). These patients had already been subjected to neurocognitive evaluation five years previously. Demographic, clinical and analytical data were analysed. For the neurocognitive evaluation, the WAIS-III subtests (digit symbol coding and symbol search), trail making test (TMT) A and B, Stroop test and categorical verbal fluency (animals) tests were used. SPSS ${ }^{\circledR}$ version 22.0 for Windows was used for statistical analysis. Results: In this re-evaluation, performed $4.76( \pm 1.82)$ years after the first one, $9(36 \%)$ patients showed deficits in processing speed (WAIS-III and TMT A), 8 (32\%) executive function (TMT B and Stroop) and $12(48 \%)$ verbal fluency. There were significant statistical differences between the past and current executive function tests $(p=$ 0.029 and $p=0.01$ ), highlighting worsening of deficits. No differences were found for the other tests. No association was found between deficit progression and the studied variables. Conclusions: Although not generally noticed on regular appointments, in this small population, worsening of executive function deficits (mental flexibility and divided attention) was found. Classical risk factors for HAND did not appear to interfere in its progression. Speed of
\end{abstract}


information processing and categorical verbal fluency remained stable.

\section{Keywords}

HIV, HAND, Dementia, Impairment

\section{Introduction}

Since the discovery of the human immunodeficiency virus (HIV) and the first descriptions of the acquired immunodeficiency syndrome (AIDS), more than 30 years ago [1] [2] [3], major advances in diagnosis and treatment were made. However, HIV-associated neurocognitive disorder (HAND) [4] continues to be a spectrum of neuropsychological manifestations difficult to characterize and for which the benefit of antiretroviral therapy (ART) hasn't been determined [5].

Several cross-sectional studies state that half of HIV-infected patients have some form of cognitive impairment [6] [7], and AIDS patients score consistently worse than healthy controls [8] [9]. Although severe forms are now rare, milder forms remain common and usually unnoticed [10]. These deficits can have a major impact on the ability to perform daily tasks and on quality of life [10] [11].

The spectrum of HAND is wide, so in 2007 the criteria of Frascati were established to distinguish three subclasses of increasing severity in terms of cognitive and functional status: asymptomatic neurocognitive impairment, mild neurocognitive disorder, and HIV-associated dementia [12]. These disorders and their degree of impact are influenced by biological factors related to HIV and chronic infection neurodegeneration [13] [14] [15] [16], as well as psychological, demographic and social factors [17] [18] [19].

There are several comparative cross-sectional case-control studies, but few longitudinal studies to assess the development of neurocognitive status in patients with HIV infection and risk factors such as immune, viral and clinical status or combined therapy may have in HAND. The Portuguese population has a particular context: most of HIV-infected patients have low education and socio-economic level [20], but have access to ART, medical and psychological care free of charge and, as a result, great adherence and positive developments on morbidity and mortality are registered.

Since the impact of ART seems irrelevant related to HAND development, we proposed to carry out the second neurocognitive evaluation in patients on ART with suppressed viral load for 10 years, assess their cognitive and functional evolution, and evaluate the impact of biological, psychological and social variables.

\section{Methods}

The study of neurocognitive function of HIV patients followed in the Infectious Diseases Department of São João Hospital Centre, in Oporto, is a continuous 
longitudinal analysis previously approved by the hospital's Ethics Committee. Fifty nine of suppressed patients evaluated for the first time in 2008 [21] were summoned for a second neurocognitive evaluation between January and June 2014. Twenty-five patients agreed to be subjected again to psychological evaluation. All these patients were on ART and had viral suppression for over 10 years. Patients with history of blips were also included.

Psychological tests were conducted by certified psychologists. Analysis of processing speed was conducted using the sub-tests of Wechsler Adult Intelligence Scale-III (WAIS-III) (digit symbol coding and symbol search) for information processing speed evaluation and the trail making test (TMT) A. Executive function analysis was performed using TMT B and the Stroop test. Categorical verbal fluency was evaluated testing for name of animals. Only approved psychological tests for the Portuguese population and previously described in patients with HIV were used [22] [23].

Data were collected and analysed regarding age, gender, education, time since HIV diagnosis, initial viral load, time to viral suppression, nadir of CD4+ T lymphocyte count, current count of CD4+ T lymphocytes, number of blips, ART regimen, ART central nervous system (CNS) penetration score, clinical stage of disease, previous history of CNS opportunistic infections, current or previous diagnosis of depression, and current therapy prior to depression.

Data processing and statistical analysis was performed using the SPSS ${ }^{\circledR}$ version 22.0 for Windows operating system. The existence of a statistical relation between the results obtained in the current psychological tests and those five years before using simple linear regression was firstly assessed. Then, whether there was a statistically significant difference between these results using the $\mathrm{T}$ test for paired samples. Different demographic, clinical, analytical and psychological variables ( $\mathrm{T}$ test for independent samples and X2 test for a 5\% significance level) were then tested for correlation.

\section{Results}

Out of the 25 evaluated patients (Table 1), 13 (52\%) were male and 12 (48\%) were female, with a mean age of $44.48( \pm 4.34)$. Patients were infected for a mean 17.52 years $( \pm 3.83)$, with viral suppression under ART for a mean 11.34 years $( \pm 1.31)$, and mean time to suppression of 59 weeks (1.13 years).

Median initial viral load was $93143 \mathrm{cp} / \mathrm{mL}$ (min. 342, max. 750000), with a median CD4+ nadir of $282 / \mathrm{mm}^{3}$ (min. 12 , max. 625 ), and a median CD4+ count at the second neurocognitive evaluation $660 / \mathrm{mm}^{3}$ (min. 411, max. 1206). Ten patients had blips (40\%), with an average of 1.7 blips per patient.

Regarding ART at the second neurocognitive evaluation, 22 patients (88\%) were under triple therapy. The most used backbone was emtricitabine/tenofovir (FTC/TDF), in 12 patients, 7 were on abacavir/lamivudine (ABC/3TC) and 3 were on zidovudine/lamivudine (AZT/3TC). Mean ART CNS penetration score was $7.68( \pm 1.35)$.

Seven patients (28\%) had AIDS, and none had a previous history of CNS 
Table 1. Descriptive and inference statistics of clinical, analytical and demographic variables ( $\mathrm{p} \leq 0.05$, CI 95\%).

\begin{tabular}{lccc}
\hline \multirow{2}{*}{ Variables } & \multicolumn{3}{c}{ Statistical analysis } \\
\cline { 2 - 4 } & Results & TMT-B (p) & Stroop (p) \\
\hline Gender & Female $52 \%$, Male $48 \%$ & 0.025 & 0.910 \\
Age (mean) & $44.48 \pm 4.34$ & 0.207 & 0.907 \\
Schooling (years) & $6.6 \pm 3.28$ & 0.828 & 0.267 \\
Disease duration (years) & $17.52 \pm 3.83$ & 0.678 & 0.070 \\
CD4+ nadir (/mm $\left.{ }^{3}\right)$ & $282[12 ; 625]$ & 0.192 & 0.490 \\
Time to suppression (mean) & 59 weeks & 0.656 & 0.712 \\
CD4+ at 10 years of suppression $\left(/ \mathrm{mm}^{3}\right)$ & $660[411 ; 1206]$ & 0.572 & 0.534 \\
ART CNS penetration score & $7.68 \pm 1.35$ & 0.234 & 0.756 \\
Blips & 1.7 & 0.461 & 0.975 \\
AIDS stage & $28 \%$ & 0.344 & 0.478 \\
Depression & $24 \%$ & 0.629 & 0.659 \\
\hline
\end{tabular}

disease. Six patients (24\%) had depression and were on anti-depressant therapy; other 3 were on methadone. Patients had a mean schooling of 6.6 years $( \pm 3.28)$ : 8 (32\%) completed elementary studies (4 years), 11 patients (44\%) 5 patients (20\%) completed middle school (9 years), and only one had university-level education.

In this cognitive evaluation, done at 10 years of viral suppression, 17 patients (68\%) showed impairment of processing speed in the WAIS-III test code, 11 patients (44\%) in the WAIS-III test symbols, and $9(36 \%)$ in TMT-A. Eight patients (32\%) showed deficit in all processing speed tests. Regarding executive function, 19 patients (76\%) scored as deficit in the Stroop test. Eight patients (32\%) had the same result in the TMT-B. Twelve patients (48\%) showed categorical verbal fluency deficit.

Performing simple linear regression between both previous ( 5 years before) and current results (Figure 1), a statistically significant association was found exclusively in the executive function tests (TMT-B, $p=0.029$ and Stroop, $\mathrm{p}=$ 0.01 ). The mean difference between both evaluations was 1.167 and 5.560 for TMT-B and Stroop. This means that only in these trials were the current scores dependent on the first evaluation, and they evolved significantly. The positive difference between the scores points to a global worsening of executive function in this sample of HIV patients.

The difference of mean scores in executive function tests TMT-B and Stroop was then recoded into the categorical variables "worsened" and "not worsened" and a statistically significant association with clinical, analytical and demographic variables (Table 1) was analysed. Such an association was only found with gender-only one woman showed executive function deficit $(p=0.025)-$ but only in the TMT-B test. 

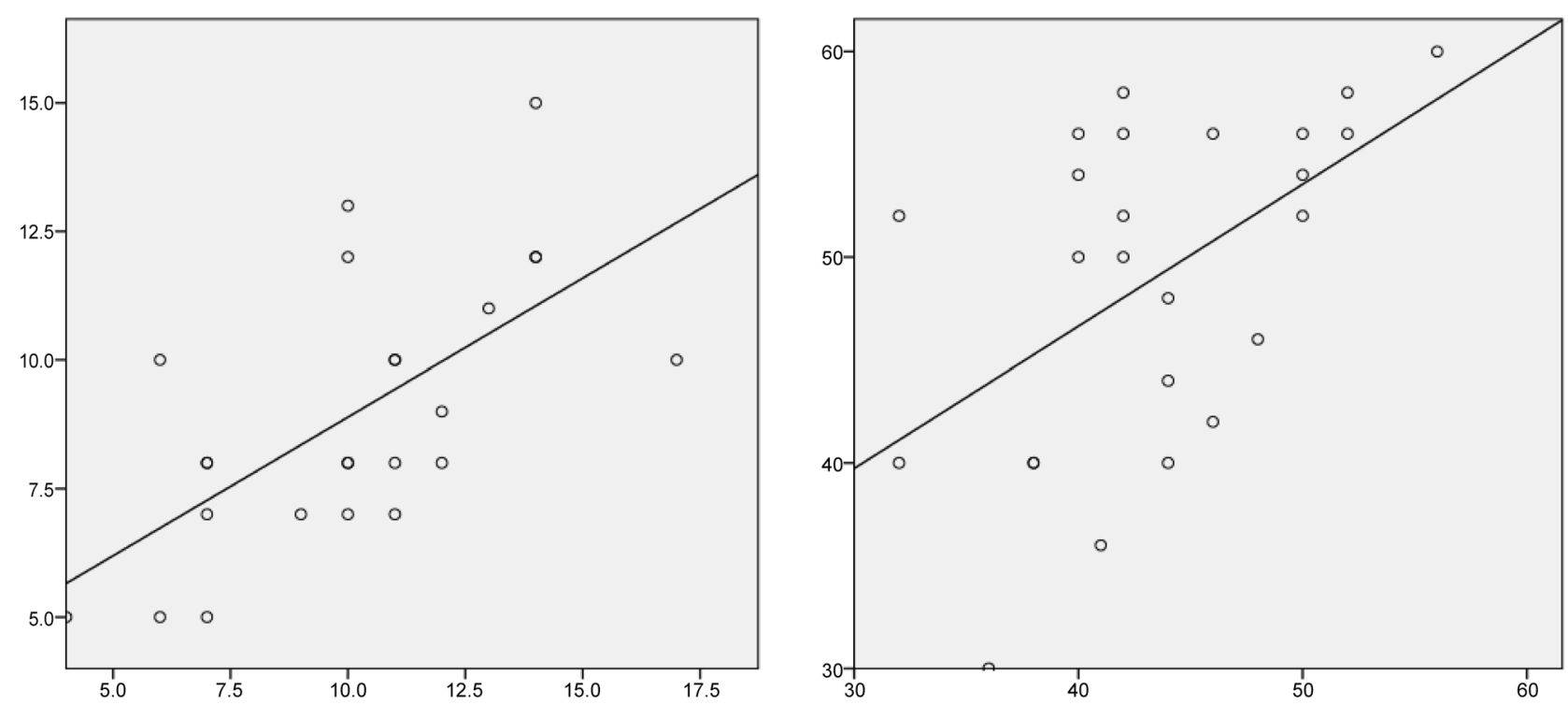

Figure 1. Linear regression analysis of the TMT B (left) and Stroop (right) tests showing correlation between previous (5 years) and current results.

\section{Discussion}

The impact of HIV infection in the CNS has been described since the beginning of the epidemic. In Portugal, there is insufficient data about the effects of HIV infection on neurocognitive impairment. Thus the importance of these studies: to characterize the Portuguese population and highlight the diagnosis difficulty of HAND on consultation and its associated morbidity. The difficulty of diagnosis is also based on its clinical variability: patients may show signs of cognitive recovery with ART or signs of escalation with the disease progression; they can either present a static or a fluctuant course [9].

In our study, only executive function presented a significant direct association with the first performance, and a clear cognitive deterioration was found in this domain. Executive function includes organizing capacity and a behavioural answer to solve a complex problem, remote memory activation, independent behaviour and adaption capacity in different contexts through verbal skills. These deficits are associated to frontal lobe lesion [24] and previous studies seem to demonstrate that this is the main cognitive domain affected by the HAND spectrum [25].

Processing speed and verbal fluency tests haven't scored statistically different between evaluations, so a linear correlation wasn't demonstrated. This means that any existing fluctuation in these domains was probably due to external factors and not because of HIV infection or its therapy.

When variables age, AIDS, CD4+ count, schooling, ARV CNS penetration score, blips, depression or other CNS disease, disease evolution (years) or time to supressed viral load (months) were analysed, no statistically significant association with the clear executive function deterioration was found. However, there seems to be a tendency for patients with longer duration of disease to present a more evident impairment (Stroop; $\mathrm{p}=0.07$ ), and the same can be said to pa- 
tients with depression (TMT-B; $\mathrm{p}=0.132$ ). Otherwise, in our sample, female sex was associated with less severe worsening, given that only one woman had executive function impairment, against 9 men (TMT-B; $\mathrm{p}=0.025$ ).

These results may be due to sampling limitation. It's possible that with a larger sample, the influence of duration of disease and cognitive decline would be unequivocal and, on the contrary, there wouldn't be any difference between sexes. Reasons to believe this are the demonstrated association between longer time of disease and higher risk of other complications associated with HIV [26] [27], and the absence of any study that demonstrates that women have a diminished risk of developing HAND.

Neurocognitive impairment, when present, is difficult to detect in a routine consultation and may not be clinically significant during the initial stage of HIV infection. A multidisciplinary intervention is, then, important, with psychologists, psychiatrists and neurologists taking part. Although the observed deficits in this study are small, they are clinically relevant. These patients are more likely to have a lower quality of life and a higher difficulty dealing with daily life activities. Consequently, this may affect adherence to treatment.

The main limitations of this study are its narrow population study (patients with HIV on treatment and with supressed viral load) and reduced sample size. Another important limitation is the fact that almost all cognitive tests cited in international literature, some with clinical relevance on HIV infection, aren't validated in the Portuguese population. However, our findings are consistent with those of other publications, supporting the validity of these results.

\section{Conclusions}

Albeit the progress of HIV treatment and a subsequent higher survival, patients still have a risk of neurocognitive degeneration, and its evolution isn't detectable in a usual appointment. In this small sample we found worsening of executive function (mental flexibility and divided attention) that is not related to immune recovery, adherence, response to treatment or other clinical hotspots usually highlighted during consultation.

Risk factors classically associated to HAND don't seem to interfere with its progression. More longitudinal studies with larger samples, with a more heterogeneous population and with a wider array of psychological tests are welcome in order to further validate, or refute, our findings, as well as to better characterize the way in which HAND progresses.

\section{Acknowledgements}

The authors would like to acknowledge Miguel Bragança, Ana Sofia Santos and Rui Marques for conducting the first neuropsychological evaluation five years prior to the current one and setting the stones for this project.

\section{References}

[1] Barre-Sinoussi, F., Chermann, J.C., Rey, F., Nugeyre, M.T., Chamaret, S., Gruest, J., 
et al. (1983) Isolation of a T-lymphotropic Retrovirus from a Patient at Risk for Acquired Immune Deficiency Syndrome (AIDS). Science, 220, 868-871. https://doi.org/10.1126/science.6189183

[2] Gottlieb, M.S., Schroff, R., Schanker, H.M., Weisman, J.D., Fan, P.T., Wolf, R.A., et al. (1981) Pneumocystis carinii Pneumonia and Mucosal Candidiasis in Previously Healthy Homosexual Men: Evidence of a New Acquired Cellular Immunodeficiency. The New England Journal of Medicine, 305, 1425-1431. https://doi.org/10.1056/NEJM198112103052401

[3] Siegal, F.P., Lopez, C., Hammer, G.S., Brown, A.E., Kornfeld, S.J., Gold, J., et al. (1981) Severe Acquired Immunodeficiency in Male Homosexuals, Manifested by Chronic Perianal Ulcerative Herpes Simplex Lesions. The New England Journal of Medicine, 305, 1439-1444. https://doi.org/10.1056/NEJM198112103052403

[4] Grant, I., Atkinson, J.H., Hesselink, J.R., Kennedy, C.J., Richman, D.D., Spector, S.A., et al. (1988) Human Immunodeficiency Virus-Associated Neurobehavioural Disorder. Journal of the Royal College of Physicians of London, 22, 149-157.

[5] Foley, J., Ettenhofer, M., Wright, M. and Hinkin, C.H. (2008) Emerging Issues in the Neuropsychology of HIV Infection. Current HIV/AIDS Reports, 5, 204-211.

https://doi.org/10.1007/s11904-008-0029-x

[6] Schouten, J., Cinque, P., Gisslen, M., Reiss, P. and Portegies, P. (2011) HIV-1 Infection and Cognitive Impairment in the cART Era: A Review. AIDS, 25, 561-575. https://doi.org/10.1097/QAD.0b013e3283437f9a

[7] Spudich, S. and Gonzalez-Scarano, F. (2012) HIV-1-Related Central Nervous System Disease: Current Issues in Pathogenesis, Diagnosis, and Treatment. Cold Spring Harbor Perspectives in Medicine, 2, a007120. https://doi.org/10.1101/cshperspect.a007120

[8] Christo, P.P. (2010) Cognitive Alterations Associated with HIV-1 Infection and AIDS. Revista Da Associacao Medica Brasileira, 56, 242-247.

[9] Woods, S.P., Moore, D.J., Weber, E. and Grant, I. (2009) Cognitive Neuropsychology of HIV-Associated Neurocognitive Disorders. Neuropsychology Review, 19, 152-168. https://doi.org/10.1007/s11065-009-9102-5

[10] Rai, Y. (2011) Factors Associated with Neuropsychological Impairment in HIV Infection. InTech, Rijeka.

[11] Tozzi, V., Balestra, P., Galgani, S., Murri, R., Bellagamba, R., Narciso, P., et al. (2003) Neurocognitive Performance and Quality of Life in Patients with HIV Infection. AIDS Research and Human Retroviruses, 19, 643-652. https://doi.org/10.1089/088922203322280856

[12] Antinori, A., Arendt, G., Becker, J.T., Brew, B.J., Byrd, D.A., Cherner, M., et al. (2007) Updated Research Nosology for HIV-Associated Neurocognitive Disorders. Neurology, 69, 1789-1799. https://doi.org/10.1212/01.WNL.0000287431.88658.8b

[13] Gonzalez-Scarano, F. and Martin-Garcia, J. (2005) The Neuropathogenesis of AIDS. Nature Reviews Immunology, 5, 69-81. https://doi.org/10.1038/nri1527

[14] Martin-Garcia, J., Cao, W., Varela-Rohena, A., Plassmeyer, M.L. and Gonzalez-Scarano, F. (2006) HIV-1 Tropism for the Central Nervous System: BrainDerived Envelope Glycoproteins with Lower CD4 Dependence and Reduced Sensitivity to a Fusion Inhibitor. Virology, 346, 169-179.

[15] Gartner, S. (2000) HIV Infection and Dementia. Science, 287, 602-604. https://doi.org/10.1126/science.287.5453.602

[16] Braganca, M. and Palha, A. (2011) HIV Associated Neurocognitive Disorders. Actas Españolas de Psiquiatría, 39, 374-383. 
[17] Maj, M., Satz, P., Janssen, R., Zaudig, M., Starace, F., D’Elia, L., et al. (1994) WHO Neuropsychiatric AIDS Study, Cross-Sectional Phase II. Neuropsychological and Neurological Findings. Archives of General Psychiatry, 51, 51-61. https://doi.org/10.1001/archpsyc.1994.03950010051007

[18] Satz, P., Morgenstern, H., Miller, E.N., Selnes, O.A., McArthur, J.C., Cohen, B.A., et al. (1993) Low Education as a Possible Risk Factor for Cognitive Abnormalities in HIV-1: Findings from the Multicenter AIDS Cohort Study (MACS). Journal of Acquired Immune Deficiency Syndromes, 6, 503-511. https://doi.org/10.1097/00126334-199305000-00011

[19] Stern, R.A., Silva, S.G., Chaisson, N. and Evans, D.L. (1996) Influence of Cognitive Reserve on Neuropsychological Functioning in Asymptomatic Human Immunodeficiency Virus-1 Infection. Archives of Neurology, 53, 148-153.

https://doi.org/10.1001/archneur.1996.00550020052015

[20] Diniz, A.D.R., Bettencourt, J., Melo, T., Gomes, M. and Oliveira, O. (2015) Infeção por VIH, SIDA e Tuberculose em números-2015. In: Saúde, D.-G.d., Programa Nacional para a infecção VIH/SIDA, Ministério da Saúde, Brasília.

[21] Braganca, M. and Palha, A. (2011) Depression and Neurocognitive Performance in Portuguese Patients Infected with HIV. AIDS and Behavior, 15, 1879-1887. https://doi.org/10.1007/s10461-011-9973-3

[22] Gladsjo, J.A., Schuman, C.C., Evans, J.D., Peavy, G.M., Miller, S.W. and Heaton, R.K. (1999) Norms for Letter and Category Fluency: Demographic Corrections for Age, Education, and Ethnicity. Assessment, 6, 147-178. https://doi.org/10.1177/107319119900600204

[23] Wechsler, D. (1958) The Measurement and Appraisal of Adult Inteligence. 4th Edition, Williams \& Witkins, Baltimore. https://doi.org/10.1037/11167-000

[24] Mega, M.S. and Cummings, J.L. (1994) Frontal-Subcortical Circuits and Neuropsychiatric Disorders. The Journal of Neuropsychiatry \& Clinical Neurosciences, 6, 358-370. https://doi.org/10.1176/jnp.6.4.358

[25] Reger, M., Welsh, R., Razani, J., Martin, D.J. and Boone, K.B. (2002) A Meta-Analysis of the Neuropsychological Sequelae of HIV Infection. Journal of the International Neuropsychological Society, 8, 410-424. https://doi.org/10.1017/S1355617702813212

[26] Aad, G., Abajyan, T., Abbott, B., Abdallah, J., Abdel Khalek, S., Abdinov, O., et al. (2013) Measurement of Top Quark Polarization in Top-Antitop Events from Proton-Proton Collisions at Radicals $=7 \mathrm{TeV}$ Using the ATLAS Detector. Physical Review Letters, 111, Article ID: 232002. https://doi.org/10.1103/PhysRevLett.111.232002

[27] Bornstein, R.A., Nasrallah, H.A., Para, M.F., Whitacre, C.C. and Fass, R.J. (1994) Duration of Illness and Neuropsychological Performance in Asymptomatic HIV Infection. The Journal of Neuropsychiatry \& Clinical Neurosciences, 6, 160-164. https://doi.org/10.1176/jnp.6.2.160 
Submit or recommend next manuscript to SCIRP and we will provide best service for you:

Accepting pre-submission inquiries through Email, Facebook, LinkedIn, Twitter, etc. A wide selection of journals (inclusive of 9 subjects, more than 200 journals)

Providing 24-hour high-quality service

User-friendly online submission system

Fair and swift peer-review system

Efficient typesetting and proofreading procedure

Display of the result of downloads and visits, as well as the number of cited articles Maximum dissemination of your research work

Submit your manuscript at: http://papersubmission.scirp.org/

Or contact wja@scirp.org 